\title{
“CAPITOLS DEL STABLIMENT DE TURBALLOS", 1515
}

\author{
Primitivo J. Pla Alberola
}

Universidad de Alicante

En un artículo ya clásico, aparecido hace ahora cuarenta años, Gual Camarena lamentaba la falta "de monografías, ediciones y estudios adecuados" sobre los mudéjares '. Desde entonces, la labor realizada ha permitido avanzar notablemente en el análisis de esa importante minoría y en el de sus inmediatos sucesores: los moriscos. Sin embargo, en fechas mucho más recientes, tanto Guichard, al referirse a los mudéjares, como García Cárcel, al hablar de los moriscos, aluden a las importantes lagunas de nuestro conocimiento sobre las relaciones con la tierra de las minorías islámicas en la Valencia bajomedieval y moderna ${ }^{2}$.

Cabe hablar de lagunas pese a que la información disponible es relativamente abundante ${ }^{3}$. Por un lado, porque ésta todavía no permite trazar un cuadro coherente en un ámbito caracterizado por las grandes diferencias de índole local; por otro, porque se barajan determinados documentos haciendo abstracción del contexto en el que se gestan, sin tener en cuenta que algunos de los derechos que es posible documentar dependen de las prerrogativas jurisdiccionales que ejerciese el señor -jurisdicción baronal, alfonsina, civil o ínfima-y otros de circunstancias muy particulares que no es prudente olvidar, como el análisis del caso que nos ocupa pondrá de manifiesto.

1 GUAL CAMARENA, Miguel: "Mudéjares valencianos. Aportaciones para su estudio". Saitabi (Valencia), números 33-34 (1949), p. 167.

2 GUICHARD, Pierre: "La repoblación y la condición de los mudéjares". En Nuestra Historia. Mas-Ivars ed., Valencia, 1980, vol. III, pp. 70-73. GARCIA CARCEL, Ricardo: "La historiografía sobre los moriscos españoles. Aproximación a un estado de la cuestión'. Estudis (Valencia), no 6 (1977), p. 98.

3 Una bibliografía amplia y actualizada puede encontrarse en BURNS, Robert I.: Colonialisme medieval. Tres i Quatre. Valencia, 1987, $482 \mathrm{pp}$. Prueba de la creciente atención que merecen estos temas es que aún se pueden añadir importantes trabajos posteriores, aunque por su cronología se alejen un tanto del período que centra nuestra atención, como el de GUINOT RODRIGUEZ, Enric: Feudalismo en expansión en el norte valenciano. Diputació de Castelló. Castellón de La Plana, 1986, 446 pp.: y el de DIAZ MANTECA, Eugenio: El 'Libro de Poblaciones y Privilegios' de la Orden de Santa Maria de Montesa (1234-1429). Diputació de Castelló, Castellón de la Plana, 1987, 489 pp. 
Turballos, actualmente una aldea casi despoblada del término de Muro -en el interior de la provincia de Alicante-, entra en la historia escrita con el Repartiment, cuando Jaime I concede a P. de Bosch "alqueriam que dicitur Torbayllos, totam integre per hereditatem francham, exceptis furnis et molendinis" " 4

A partir de entonces, Turballos constituye un pequeño señorío ubicado en los términos generales de Cocentaina, sin que nos hayan llegado noticias de roces con los sucesivos señores de la villa, pese a lo frecuentes que fueron los mantenidos por éstos con los titulares de otros pequeños señoríos desde la primera mitad del siglo XIV ${ }^{5}$. No es posible determinar si los señores de Turballos llegaron a ejercer la jurisdicción alfonsina o sólo niveles inferiores de competencias, pero en todo caso su personalidad jurisdiccional está reconocida en documentos como los capítulos de las sisas de 1457 , cuando se declaró que los hombres de Turballos no estaban obligados a satisfacer las decretadas por el consell de Cocentaina ${ }^{6}$.

Sabemos que en 1358 era señor de Turballos un tal Berenguer de Fabra, vecino de Valencia $^{7}$, y tenemos referencias, más o menos directas, a posteriores enajenaciones de esta alquería: el 13 de octubre de 1407 Galcerán de Loriz la vende a Martín Ruiz ${ }^{8}$; medio siglo después, el 1 de abril de 1452, Juan Satorre y su mujer hicieron otro tanto en favor de D. Ximén, primer conde de Cocentaina ${ }^{9}$.

Desde entonces, Turballos quedará integrado en el condado de Cocentaina y, en su caso, sus rentas arrendadas con las restantes de este señorío. Pero, pese a ello, Turballos continuó siendo una unidad de gestión económica, al igual que otros señoríos antes independientes que fueron adquiridos por los sucesivos barones de Cocentaina, lo cual hacía que, en ocasiones, el arrendatario del condado optase por subarrendar la percepción de las rentas de Turballos.

Uno de estos subarrendamientos, apenas dos décadas posterior a la compra de Turballos por D. Ximén, evidencia que esta adquisición supuso una inversión importante: por la "alquarea vulgariter dicta de Torballos, sita et posita in dicto comitatu" -con todos los derechos, "redditus, emolumentis, besantis et omnia alia jura, excepto jus criminalis", y reconociendo que los "prestechs quos agarenis dicte alquaree de presenti habent sunt vestri proprie"-, el subarrendatario debía satisfacer 2.000

4 CABANES PECOURT, M" Desamparados y FERRER NAVARRO, Ramón (eds.): Libre del Repartiment del Regne de València. Anúbar ed., Zaragoza, 1979, vol. II, n" 839.

5 PLA ALBEROLA. Primitivo J.: Conflictos jurisdiccionales en un gran señorio valenciano: el condado de Cocentaina ante la consolidación del absolutismo. Tesis doctoral inédita, Alicante, 1985, pp. 88 y ss.

6 Archivo Municipal de Cocentaina (A.M.C.): Consells, $\mathrm{n}^{\circ} 5, \mathrm{f}^{\circ} 24 \mathrm{v}^{\circ}$.

7 ARQUES JOVER, Agustín: Notas varias y extracto de los notarios, archivos y otros papeles e instrumentos de la villa de Cocentaina... ms. de fines del siglo XVIII conservado en el Archivo Parroquial de Santa María de Cocentaina, vol. VII, fo $32 v^{\circ}$.

8 Archivo Ducal de Medinaceli, Sevilla (A.D.M.): Sección Cocentaina, 7/1.

9 A.D.M.: Sección Cocentaina, 7/2. 
sueldos anuales ${ }^{10}$, cuando el conjunto del condado estaría arrendado en algo más de 20.000 sueldos ${ }^{11}$.

Poco es lo que podemos decir de Turballos en vísperas de los establecimientos de 1515, pues las referencias a este lugar en la documentación consultada son parcas en extremo, pero con ayuda de la generada inmediatamente después podemos perfilar algunas características que conviene tener en cuenta.

Turballos era una pequeña población de 14 ó 15 familias de mudéjares que constituían una comunidad local regida por "alamí e aljames". Los residentes en el lugar estaban obligados a satisfacer al conde el besante, "servitut de lenya, obra, coreus, cavar la vinya, acuts com altra qualsevol servitut", al igual que los demás mudéjares del condado. Es de suponer, por lo tanto, que también los hombres de Turballos vieran modificados algunos de los gravámenes que soportaban a fines del siglo XV y principios del XVI, cuando, por ejemplo, el conde conmutó por un pago fijo anual en metálico su derecho a percibir la herencia de quienes morían sin herederos directos en el condado.

Si estas modificaciones pudieron suponer una mejora relativa en la situación de los mudéjares, otras documentadas en fechas próximas obraron en sentido contrario. En 1497, tras adquirir la mujer del conde D. Juan un molino próximo a Gayanes y Turballos, los mudéjares residentes en dichos lugares expusieron cómo habían sido "per vostra spectable senyoria [el conde de Cocentaina] stats exortats, pregats e manats que (...) volguesen venir a molre al dit molí (...) ab dret de gabella que nenguna persona de dits lochs no puxen anar ni enviar molre a altre molí (...), sots pena de sexanta sous". Por supuesto, no pudieron ignorar tales requerimientos, y, claro es que sólo "per fer servey a sa spectable senyoria", los vasallos se declararon "contents anar a moure (sic) al dit molí de Celha" "12.

Servicios personales, derecho de herencias, besantes, maquila... Carezco de datos que permitan determinar su incidencia económica a principios del XVI; ahora bien, quizás estos derechos no fuesen los más gravosos: tengamos en cuenta que el ejercicio de la jurisdicción reportaba a los barones -término que en Valencia definía a los señores con mero y mixto imperio- unos ingresos en modo alguno despreciables; pero, sobre todo, el que los mudéjares de Turballos y de las demás localidades del condado, por su condición de vasallos, estuviesen obligados a proporcionar a su señor un auxilio cuyas manifestaciones más frecuentes eran servicios en metálico y préstamos "voluntarios", también era importante el que los bienes del vasallo fuesen garantes natos de las deudas del señor y, muy especialmente, el que todos los vasallos estuviesen sometidos a un poder de mando - temible, por cuanto no existía la posibilidad de recurrir al

10 Archivo del Colegio del Patriarca, Valencia (A.C.P.): Protocolos de Guillem Peris, sig. 1.698.

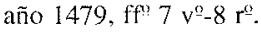

11 En 1446 fue arrendado por 21.000 sueldos y en 1498 por 25.000 , un aumento que en buena parte parece atribuible a las adquisiciones realizadas por los condes de distintos bienes, como el mismo señorío de Turballos.

12 A.C.P.: Protocolos de Guillem Peric, sig. 1.698, año 1497, sin foliar, escra. de 30 de agosto. 
rey ni cuando el barón laico dictase pena de muerte sin proceso- que constituía, en último extremo, el fundamento de $\operatorname{los}$ monopolios señoriales ${ }^{13}$, como hemos tenido ocasión de ver.

Los citados hasta ahora son derechos que podemos considerar comunes a todos los mudéjares del condado, aunque quepa establecer algunas matizaciones locales. No ocurre lo mismo en el terreno de las rentas agrarias, pues en él encontramos tales diferencias que es improcedente cualquier intento de generalización y es imposible deducir la situación existente en Turballos extrapolando la documentada en localidades vecinas. De todas formas, es posible determinar cuáles serían sus principales características a partir de los escasos datos disponibles. Hemos visto que se habla de Turballos como una alquería, y de la caracterización que de las alquerías hice en otra ocasión ${ }^{14}$ puede deducirse que los residentes en Turballos cultivarían sus tierras en un régimen de aparcería de tradición islámica que apenas les reconocía derecho alguno sobre ellas ${ }^{15}$.

Este planteamiento, por lo demás, viene confirmado por los términos en que se expresa el mismo representante del conde en un pleito que más adelante comentaremos: las tierras de Turballos "no eren pròpries dels moros sinó que eren heretats del dit comte, les quals aquell donava a miges als dits moros, e axí mateix les podia cultivar ab sos moros si volguera" 16 . Ahora bien, nada permite determinar la participación de las partes -señor y cultivador directo- en la producción final, por ello no está de más recordar cuál era la situación en señoríos vecinos cuyas tierras eran explotadas mediante un régimen de tenencia similar: el señor percibía entre la mitad y la tercera parte de los granos de regadío, entre la tercera y la cuarta parte en el secano y la mitad de los frutos -e incluso las dos terceras partes-- en el caso de cultivos arbóreos y arbustivos ${ }^{17}$; es decir, el señor obtenía un rendimiento de sus posesiones difícilmente superable, y es de suponer que al cultivador directo de esas tierras apenas le quedaba, como fruto de su trabajo, lo suficiente para asegurar su supervivencia y la de los suyos.

13 Para todas estas cuestiones véase mi tesis doctoral, ya citada en n. 5.

14 PLA ALBEROLA, Primitivo J.: "Condiciones de tenencia de la tierra y jurisdicción en el siglo XVI valenciano. Hacia una tipificación de las alquerías moriscas". En La propiedad rústica en España y su influencia en la organización del espacio. Departamento de Geografía, Alicante, 1981, pp. 53-63.

15 Véanse también mis trabajos "Acerca de los contratos agrarios de los mudéjares valencianos: los 'capítols" de Catamarruc'. Anales de la Universidad de Alicante. Historia Medieval (Alicante), $\mathrm{n}^{\prime} 2$ (1983), pp. 119-138. Y "Exáricos valencianos". En España y el norte de Africa. Publicaciones de la Universidad de Granada, Granada, 1987, vol. I, pp. 391-398.

16 Loc cit. infra n. 33. Expresiones similares en la suplicación presentada por la parte contraria (loc. cit. infra n. 34) si bien no reconoce expresamente que éste fuese el régimen de tenencia, pues habla en términos muy genéricos de la "antigua consuetut" vigente hasta 1515 de "tant de temps que memòria de hòmens no és en contrari" y, de forma que considero impropia - y quizá interesada--, de "los moros que tenien poblat lo dit loch ans de la dita despoblació" de 1515; tengamos en cuenta que D. Rodrigo intentaba obligar al conde D. Juan la vuelta a la situación anterior a los establecimientos de 1515 y no le interesaría reconocer semejante libertad de disposición sobre las casas y tierras por el entonces señor.

17 Trabajos citados supra nn. 14-15 y PLA ALBEROLA, Primitivo J.: "Apuntes para el estudio de las rentas señoriales en el siglo XVI. Los pequeños señoríos del 'Quartel de las Montañas" ". En Jerónimo Zurita, su época y su escuela. Institución Fernando el Católico, Zaragoza, 1986, pp. 259-265. 
El mencionado régimen de explotación de las tierras de Turballos, así como las mismas condiciones de vida de los residentes en dicho lugar, se vieron modificadas en 1515 de forma radical. Fue una transformación realizada en dos etapas, entre las cuales apenas transcurrió medio mes, aunque sólo la segunda -y que considero definitiva - la he podido documentar directamente.

El 21 de octubre de 1515 fueron establecidos en favor de "certs moros del loch de Muro" -localidad situada a escasos $3 \mathrm{~km}$. - los secanos de Turballos a censo de 6 cahíces y 8 barchillas de trigo, obligándose además los censatarios a satisfacer 8.400 sueldos en concepto de entrada ${ }^{18}$. Es lo poco que puedo decir de este primer establecimiento, pues no he podido localizar el acta notarial ${ }^{19}$ ni referencias más explícitas a las condiciones que lo regularon, pero todo apunta a que estamos ante la cesión de las tierras menos productivas del lugar a quienes serán los beneficiarios de un segundo establecimiento que comprenderá el resto de los inmuebles de Turballos, sin que sea posible determinar el porqué de este proceder.

La segunda escritura que reguló el establecimiento de Turballos es apenas unos días posterior, del inmediato 3 de noviembre ${ }^{20}$. Por ella, el conde D. Juan acensúa a veinticuatro mudéjares residentes en Muro el lugar de Turballos, con todas sus casas y tierras, "exceptat lo que ja.ls és stat stablit"; y es de suponer que aquí se alude a los secanos ya censidos a fines de octubre.

En este documento, a lo largo de sus quince capítulos, se especifican las condiciones del mencionado establecimiento a "cens, fadiga e luysme". Las prestaciones económicas que en él se contemplan están en la órbita de las fijadas el 21 de octubre. El censo es fijo y en especie, estipulándose sólo el monto total que deberán satisfacer los censatarios por el conjunto de las tierras entonces establecidas: 7 cahíces de trigo "a corrent" (cap. 1), a pagar todos los años el 15 de agosto desde 1516 (cap. 9); un censo que presumiblemente se debería distribuir entre los distintos beneficiarios, de forma proporcional a la extensión y productividad de las tierras que poseyesen ${ }^{21}$. Por

18 Según datos aportados por el procurador de D. Rodrigo ante la Real Audiencia para oponerse a estos establecimientos. Contamos con dos estimaciones, la de la súplica de 26 de octubre de 1515 (loc. cit. infra n. 32) y la de 14 de enero de 1516 (loc. cit. infia n. 34), las cuales coinciden aproximadamente en el monto total pero no en su desglose; he seguido la más tardía, presentada en un memorial más extenso y detallado, y cuyas referencias al segundo establecimiento coinciden con el documento que ha Ilegado hasta nosotros.

19 Según el memorial de 14 de enero de 1516 (loc. cit. infra n. 34) esta escrituráa pasó ante el mismo notario que la segunda: Luis Juan de Alçamora. Sus protocolos se conservan actualmente en el Archivo Municipal de Alcoy, y un volumen está dedicado al año 1515, sin embargo la última escritura que contiene es del 3 de mayo.

20 A.D.M.: Sección Cocentaina, 7/10. Este documento se transcribe como apéndice documental, por lo que las referencias al mismo se harán simplemente especificando en el texto, entre paréntesis, el capítulo de referencia.

2 I Es un proceder común en situaciones similares, aunque en este caso es imposible contrastar dicha hipótesis por no haber localizado las escrituras individuales (vid. supra n. 19). Es incluso probable que no llegaran a formalizarse, dada la rápida intervención de la Real Audiencia a instancias de D. Rodrigo y el que en los mismos establecimientos (cap. 3) se dé libertad a los censatarios para distribuir las casas y tierras entre cllos, teniendo un plazo de año y medio para intercambiar entre sí los inmuebles sin luismo ni ladiga. 
otro lado, también ahora se fija una entrada de 16.800 sueldos (cap. 2). Es decir, en conjunto, el conde debería percibir por los bienes establecidos en Turballos una renta anual de 13 cahíces y 8 barchillas de trigo y una entrada de 25.200 sueldos, pagadera por mitad el primero de enero de 1517 y $1518^{22}$.

El censo cabe considerarlo moderado - aunque su carácter fijo pudiese dificultar el pago en los años de pobres cosechas-, una gracia especial el que durante año y medio los censatarios pudiesen transportar entre ellos las casas y tierras francas de luismo y fadiga (cap. 3), pero sobre todo llama la atención la importante serie de concesiones en el terreno de las prestaciones personales y los derechos de monopolio. En este ámbito, el conde cede en favor de los censatarios la almazara del lugar (cap. 5), la carnicería (cap. 13) y el herbaje (cap. 12), reteniendo tan sólo la casa de la señoría (cap. 4), el tercio diezmo (cap. 4), la parte del señor en "clams e calonies" (cap. 12) y es de suponer que la jurisdicción civil y criminal. Además, el documento contiene un amplio abanico de franquicias: licencia para arrancar cualquier tipo de árbol -excepto olivos- (cap. 7), exención general de las gabelas - por lo que los censatarios pueden llevar las aceitunas y granos a moler donde estimen conveniente--, de peitas, sisas y otros derechos (cap. 8); y a quienes fijen su residencia en Turballos también los exime de "servitut" de leña, peonadas, correos, jornales en las viñas del señor y cualquier otra prestación de carácter personal, excepto del besante (cap. 14).

Huelga advertir que estamos ante un conjunto de concesiones tan favorable que hizo que los mudéjares de Turballos alcanzasen una situación de privilegio entre sus correligionarios del condado, si no en cuanto a las rentas agrarias - terreno en el que hay una gran diversidad de situaciones, desde mudéjares que eran propietarios de tierras francas o con censos completamente devaluados, casi simbólicos, hasta los que eran aparceros sin derecho alguno sobre la tierra que cultivaban- sí por las franquicias de derechos de monopolio y servidumbres personales. Toda esta serie de concesiones tiene una segunda lectura, es obvio que el conde vio mermados sus ingresos ordinarios en Turballos: estimar la importancia de esta merma es difícil, pero pudo suponer hasta el $80 \%$ de la renta anual ${ }^{23}$.

La razón que explica esas concesiones tan inhabituales está clara en la escritura de noviembre, que es la que ha llegado hasta nosotros: la entrada que los censatarios debían satisfacer en un plazo de poco más de dos años. Recordemos que las entradas estipuladas en las dos escrituras suman 25.200 sueldos, una cantidad muy importante para la época -tengamos en cuenta que el condado de Cocentaina se arrendó en 1516 por 26.000 sueldos anuales ${ }^{24}-\mathrm{y}$ con una ventaja adicional: aunque el pago de las entradas se fragmentase a lo largo de dos años, estas cantidades representaban ingresos netos, sin cargas, mientras que las consignaciones de deudas hacían que el conde

22 Este aplazamiento del pago de la entrada es el pactado el 3 de noviembre, supongo que se estipularía un sistema parejo en la primera escritura.

23 Es una estimación muy arriesgada, con un carácter puramente orientativo. Valga decir que se ha tenido en cuenta como valor anterior a los establecimientos el ofrecido en el memorial presentado por D. Rodrigo ante la Real Audiencia en 1516, 120 ó 130 libras anuales (loc. cit. infra n. 34), y como el posterior el del censo en trigo al precio corriente en Valencia en 1516 (HAMILTON, Earl $\mathbf{J}$.: El tesoro americano y la revolución de los precios en España, 1501-1650. Ed. Ariel, Barcelona, 1975, p. 347).

24 Archivo Municipal de Alcoy (A.M.A.): Protocolos de Francesc Joan Alsamora, 1516, sin foliar, escra. de 18 de diciembre. 
apenas percibiese de los arrendatarios del condado lo suficiente para mantener su casa.

Estamos, por tanto, ante unos ingresos extraordinarios, atípicos, que eran especialmente interesantes para un señor fuertemente endeudado, con una acuciante necesidad de liquidez. Podemos encontrar el reflejo de esta apurada situación económica por la que atravesaba el conde de Cocentaina en los rosarios de consignaciones pactadas con los arrendatarios de sus estados, en los mismos balances de cuentas que éstos presentaban, en los requerimientos del conde a sus vasallos para que se cargasen dinero a su favor por no tener ya crédito personalmente - lo que le obligó a ceder a sus vasallos determinados derechos señoriales mientras no redimiese el censal del que era beneficiario ${ }^{25}-y$, en último extremo, en las enajenaciones de rentas y señoríos que suponían la desmembración de uno de los patrimonios señoriales más importantes de la época: venta de Penella en 1497 -aunque después volvió a adquirir este señorío--, de Aspe, Elda, Petrel y Salinas en 1498, de Agres en $1503 \ldots{ }^{26}$.

Embarcado en múltiples pleitos --contra D. Luis Ladrón de Vilanova sobre los señoríos de Dosaguas, Madrona y Pardines; contra su hermana Beatriz y contra su hermano D. Rodrigo por alimentos y derechos sobre el vínculo, entre otros ${ }^{27}$-, implicado de lleno en las banderías nobiliarias de la época - como en las de los Rocafulls y Rocamoras en Orihuela, enemistados los Corella como estaban con los Maza desde mediados del XV, parece ser que en origen por un problema de lindes entre sus respectivos señoríos de Elda y Novelda ${ }^{28}$, y sangradas sus arcas por diversos gastos extraordinarios, entre los cuales no faltaban los servicios al rey -por ejemplo, el conde fletó una galeota en la que embarcó con sus deudos y familiares para la toma de Almería ${ }^{29}-$, D. Juan parecía abocado a la ruina. Por ello, no es de extrañar que su hermano D. Rodrigo, que era quien debía heredar el condado ante la falta de hijos de D. Juan ${ }^{30}$, se opusiese a semejante dilapidación ante los tribunales del rey, obteniendo dos sentencias conformes por las que se declaraba vinculado en su favor el condado de Cocentaina $^{31}$.

En virtud de los derechos que le reconocieron las citadas sentencias, D. Rodrigo de Corella reaccionó de inmediato ante lo que constituía la enajenación de unos bienes

25 Omito una referencia puntual, que sería farragosa, a los documentos sobre el particular, especialmente interesan numerosas escrituras de los protocolos de Guillem Periç del A.C.P., de Lluis Joan Alçamora y Francesc Joan Alçamora del A.M.A.

26 A.D.M.: Sección Cocentaina, 8/3. AMAT y SEMPERE, Lamberto: Elda. (Ms. del tercer cuarto del s. XIX) Universidad de Alicante-Ayuntamiento de Elda, Alicante, 1983, vol. I, pp. 21-22. FULLANA MIRA, Luis: Historia de la Villa y Condado de Cocentaina. Publicaciones del Monte de Piedad y Caja de Ahorros de Alcoy, Alcoy, 1975 (primera ed. de 1920), pp. 345-346. $19 / 29$.

27 FULLANA MIRA, Luis: Op. cit., pp. 345-346. A.D.M.: Sección Cocentaina, 15/28, 10/18 y

28 Véase BELLOT, Mosen Pedro: Anales de Orihuela (siglos XIV-XVI). (Ms. de 1622) Publicaciones del Casino Orcelitano, Orihuela, 1954-1956, esp. vol. I, pp. 433-434; vol. II, pp. 114-117 y 138-139.

29 VICIANA, Martín de: Crónica de la inclita y coronada ciudad de Valenciar. Valencia, 1564. Ed. facsímil, Departamento de Historia Moderna de Ia Universidad de Valencia, Valencia, 1972-1983, vol. III, p. 177.

30 Originalmente estaba vinculado el señorío de Aspe, pero por escritura ante Juan de Bas el 25 de enero de 1498 se conmutó por el condado de Cocentaina (loc. cit. n. 34).

31 A.D.M.: Sección Cocentaina, 2/6 (sentencia de la Real Audiencia de 21 de febrero de 1513). Ibid., 10/22 (sentencia del Supremo Consejo de 29 de julio de 1513). Ibid., 19/29 (sentencia arbitral de 30 de octubre de 1513). 
que esperaba heredar. El 26 de octubre de 1515, incluso antes de la firma del segundo documento que hemos comentado, su procurador comparece ante la Real Audiencia solicitando la anulación de todos los actos lesivos a los intereses de su parte. De forma escueta informa de los establecimientos efectuados y de las entradas que el conde ha percibido, expone cómo resulta de ello una importante disminución de las rentas del lugar y cómo, en último extremo, "lo dit spectable comte haia desfet lo dit loch de Torballos, despoblant aquell e levant-los les heretats e terres que tenien les ha stablides als moros del loch de Muro"; denunciando también la posibilidad de que el conde iniciase actuaciones similares en el vecino lugar de La Alcudia.

Tras la preceptiva y formularia información de testigos, la Real Audiencia falla en favor del suplicante, y por provisión de 26 de noviembre, publicada en Cocentaina cinco días después, "se mana a qualsevol persones de qualsevol stat, ley e condició sien qui haien pres a emphiteosim les dites terres que no usen ne ampraven aquelles ne paguen quantitat alguna o quantitats per rahó de la entrada o entrades del dit stabliment promeses" 32.

Apenas pactado el establecimiento de Turballos, el proceso resultó interrumpido por la intervención de la Real Audiencia. Aunque la citada provisión, suplicada, no hizo desistir al conde de culminarlo con la escritura de 3 de noviembre. A partir de ese momento, por D. Juan se solicita la revocación del mandato, pretensión a la que se opone el procurador de su hermano y heredero en enero de 1516.

Interesa resumir las razones argüidas por ambas partes, tal como las exponen en sus respectivas súplicas. Aparte de cuestiones procesales y de disquisiciones sobre el carácter del vínculo que aquí importan menos, el procurador del conde considera insubsistente el argumento de que al establecimiento se seguiría la despoblación del lugar, pues ni las tierras eran de los mudéjares que allí habían residido -y en cualquier momento el conde hubiera podido gestionar directamente su cultivo - ni los mudéjares de Turballos habían abandonado el condado; por otro lado, tampoco D. Rodrigo tendría motivo para preocuparse por la disminución de su presunta herencia, pues, de llegar a sus manos, las alienaciones tendrían la consideración de temporales -sólo válidas durante la vida del estabiliente- y así "cobraria les dites heretats sens restituir les entrades" 33 .

Son argumentos que el procurador de D. Rodrigo desestima en un memorial presentado poco después. En él, pone el acento sobre el interés que tiene su parte por estar los bienes de que se trata vinculados a su favor, y considera engañoso lo alegado

32 A.D.M.: Sección Cocentaina, 7/9.

33 A.D.M.: Sección Cocentaina, 7/8. Llama la atención semejante planteamiento, sorprendentc, por inédito, a la luz de los trabajos actuales sobre cartas pueblas y documentos afines, y que tampoco se suscila en las obras de los foralistas valencianos al hablar de las relaciones entre el señor y sus vasallos. Sin embargo, no hay que desestimarlo, y al respecto conviene mencionar los planteamientos de dos importantes juristas aragoneses, Miguel de Molino y José de Sesé: el señor no está obligado a mantener lo pactado con sus vasallos, aunque jurase hacerlo, más que si son vasallos paccionados; $\mathrm{y}$, para reclamar el cumplimiento del pacto. los vasallos no podrían acudir al Justicia, a no ser que el señor, de forma expresa, se hubiese sometido a la jurisdicción de dicho magistrado ( MONSORIU, Bernardino de: Summa de todos los fueros y observancias del reyno de Aragón y determinaciones de Micer Miguel del Molino. Casa Pedro Puig y de la viuda de Joan Escarrilla, Zaragoza, 1589 (ed. facsímil, Heraldo de Aragón, 1981), f' 440. SESE, Jose de: Inhibitionum et magistratus Justitiae Aragonum. Typographie Gabrielis Graells \& Geraldi Dotil, Barcelona, 1608, I, 1, 17-19). 
por D. Juan: que el sucesor en el vínculo podría recuperar los bienes establecidos. No discute que pudiese hacerlo, pero expone cómo quedarían los vasallos en la más absoluta ruina si así procediese -perdidas las tierras y el dinero entregado en concepto de entrada-, de modo que se despoblaría el lugar sin que se pudiese recuperar a los antiguos aparceros. A continuación, el mismo procurador solicita que la parte contraria responda a las cuestiones planteadas en un articulado de dieciocho puntos, $\mathrm{y}$, si contradecía lo expuesto, pide la oportuna deposición de testigos que corrobore su veracidad. Con este documento, su procurador pretende demostrar los derechos de D. Rodrigo sobre el condado, el significado de los establecimientos de Turballos y el menoscabo que ha supuesto para sus rentas, dado que se ha reducido notablemente la participación del señor en la producción agraria, insinuando que el conde busca perjudicar a su principal de forma intencionada ${ }^{34}$.

Hasta aquí un pleito del que no he encontrado más documentación, de manera que es imposible determinar con certeza si la provisión de 26 de noviembre de 1515 obró sus efectos o se vio modificada con posterioridad, lo que es tanto como decir que desconozco cuál pudo ser la vigencia de los establecimientos de Turballos.

Sin embargo, otras vías permiten suponer que las condiciones establecidas en 1515 no tuvieron una larga vida, al menos en todos sus extremos, pues el cabreve de 1603 nos define una situación bastante diferente. Los moriscos de Turballos desconocían a principios del XVII cuál pudiera ser el documento que regulase sus relaciones con el señor, pero todos coincidían en reconocer que le satisfacían el cuarto de los productos del secano, el tercio en el caso de la "adachsa" en secano y de todos los del regadío, la mitad de los cultivos arbóreos -excepto la morera, que partía al tercio-, aparte de algunos censos en metálico, adehalas, el tercio diezmo y estar sometidos a varios monopolios señoriales ${ }^{35}$.

Vemos así que, en lugar del censo fijo en trigo estipulado en 1515, el señor tiene en 1603 una importante participación alicuota en las cosechas, que la exención de gabelas pactada casi cien años antes ya no tiene vigencia y que tampoco gozan los moriscos de Turballos de la franquicia de servicios personales concedida por el conde D. Juan. Sobre este último aspecto nada dice el cabreve de 1603, pero otra documentación contemporánea hace ver que estaba vigente un amplio abanico de servicios personales, por más que quizá muchos de ellos en desuso, de modo que fueron contestados - sobre todo por los moriscos del arrabal de Cocentaina y Muro- cuando el conde D. Gastón los quiso actualizar a partir de $1601^{36}$.

Ahora bien, lo que no podemos saber es si la evidente modificación de condiciones, que supone la revocación de los términos pactados en 1515, fue debida a la actuación de la Real Audiencia, a la actitud de D. Rodrigo cuando el 18 de junio de 1519 entró en posesión del condado ${ }^{37} \mathrm{o}$ a que fuese necesario recolonizar el lugar tras la I Germanía, de cuyas funestas consecuencias en localidades vecinas nos han llegado elocuentes testimonios.

34 A.D.M.: Sección Cocentaina, 6/59.

35 A.D.M.: Librería, 1. I/II/7, fo 112 y ss.

36 Archivo del Reino de Valencia (A.R.V.): Real Audiencia. Procesos. 1/C/379; 1/G/993; 1/G/ $1.034 ; 1 / \mathrm{S} / 1.770 ; 1 / \mathrm{S} / 1.858 ; 1 / \mathrm{S} / 1.871$ y $1 / \mathrm{S} / 1.884$.

37 A.D.M.: Sección Cocentaina, 3/10. Aunque antes de tres años pasó ab intestato a su hijo D. Guillén (ibíd, 10/7). 
Podemos hablar, en consecuencia, de un establecimiento fracasado por la concurrencia de una serie de circunstancias de tiempo y lugar muy particulares, tan particulares como aquellas otras que explicaban la benignidad de las exigencias originales del señor. De todas formas, aunque no se perpetuasen las rentas agrarias y franquicias pactadas en 1515, entonces se inicia una nueva etapa en la explotación de las tierras de Turballos: no parece que prosperase la petición del procurador de $\mathrm{D}$. Rodrigo ante la Real Audiencia, cuando solicitó se instara al conde D. Juan a restituir las tierras a sus antiguos poseedores y en las mismas condiciones; si esto llegó a hacerse tuvo también una corta vigencia, pues todo apunta a que las tierras y casas de Turballos estuvieron desde 1515 hasta 1609 censidas y no usufructuadas por aparceros. Las pruebas quizá no sean demasiado concluyentes: por un lado, el que Turballos sea citado por última vez como alquería en la súplica de 14 de diciembre de 1515; por otro, las repetidas referencias -aunque fechadas sobre todo en la segunda mitad del XVI- a las alienaciones de casas y tierras de Turballos sometidas a la directa señoría del conde ${ }^{38}$.

Quiere ello decir que, aunque la participación del señor en la producción agrícola no fuese en 1603 muy distinta a la que pudo existir hasta $1515 \mathrm{o}$ a la vigente en algunas alquerías vecinas a fines del XVI, existía una diferencia fundamental entre los moriscos de Turballos y los de, por ejemplo, Benamer: los primeros eran censatarios, tenían unos derechos sobre las tierras que cultivaban de los que podían disponer, aunque con ciertas limitaciones; unos derechos de propiedad -el dominio útil-- que les daban una estabilidad en su relación con la tierra que distaba de la existente en las alquerías, donde el señor -como en Turballos hasta 1515- podía expulsar al cultivador directo cuando quisiese y sin reconocerle más que determinados derechos sobre las cosechas pendientes ${ }^{39}$.

Por último, y a modo de epílogo, quisiese hacer una breve reflexión sobre el mismo carácter del documento que ha servido de eje articulador a estas páginas. En él, como en tantas cartas pueblas valencianas de la baja edad media y la moderna, se contempla el establecimiento a censo enfitéutico de los inmuebles de determinado lugar -en este caso en dos fases- y otras obligaciones y franquicias de los censatarios; sin embargo, en todo momento he evitado cuidadosamente el hablar de carta puebla.

Como es fácil comprender, cuando aquí lo destaco, esta omisión no es casual, sino debida a que entiendo que no nos encontramos ante una carta puebla. Desde luego, el negarle esta categoría nada tiene que ver con el hecho de que Turballos estuviese antes habitado, sino que se deduce de las mismas condiciones contenidas en la escritura de 3 de noviembre de 1515. Los beneficiarios del establecimiento son "moros comorants en lo lloch de Muro", pero en ningún momento se dice que deban renunciar a tal condición, antes bien: se les exime explícitamente de la obligación de residir en Turballos (cap. 10), aunque un aliciente para hacerla efectiva fuese el que sólo "los moros qui staran en lo dit lloch de Torballos ab son domicili e cap maior" serían los beneficiarios de las franquicias de servicios personales (cap. 14).

38 No considero necesario hacer una referencia detallada a la documentación disponible, pues se encuentra muy dispersa. Especialmente interesan las regestas que hizo Agustín Arques de protocolos hoy en buena parte desaparecidos (op. cit. supra n. 7) y las noticias sobre licencias y cobros de luismos contenidas en los libros de la Cort del Gobernador conservados en el A.M.C.

39 Véanse los trabajos citados supra nn. 14 y 15. 
Falta así en este documento uno de los requisitos fundamentales de una carta puebla: el que se proceda a la "población" del lugar, o sea al asentamiento de un grupo de familias con derechos de propiedad de la tierra y con la obligación de fijar su residencia en él. No nos debe extrañar, pues, que en el documento de los establecimientos de Turballos nunca se aluda a "poblar" o "població", términos frecuentes en todas las cartas pueblas; por ello tampoco se regulan las habituales cuestiones referidas a una comunidad local cuya génesis no se contempla ni en su forma más embrionaria; y ni siquiera se habla de vasallos, aunque puede entenderse que ésta sería una referencia ociosa por cuanto los nuevos censatarios son ya vasallos del estabiliente. Por todo ello, debemos considerar el documento comentado un contrato agrario colectivo y no una carta puebla, por más que entre ambos tipos documentales existan similitudes que han confundido a los investigadores ${ }^{40}$.

40 Véase PLA ALBEROLA, Primitivo J.: "Acerca de los contratos agrarios...", pp. 125-127. 


\section{APENDICE DOCUMENTAL}

\section{5, noviembre, 3. Muro.}

Archivo Ducal de Medinaceli: Sección Cocentaina, 7/10. Traslado notarial de 15 de diciembre de 1515 , autentificado por el mismo notario que suscribió la escritura original.

\section{Die intitulato III $^{\mathrm{a}}$ mensis novembris anno a Nativitate Domini MDXV.}

Nos, Johannes Roiz de Corella et de Moncada, comes Cocentayne, ex una parte, Catdon Benjat, Azmet Illel, Azmet Maymo, alias Carabaces, Azmet Amer, Cat Atech, Abrahim Alisar, Miques Ali, Xiti Axer, Alisar, sartor, Axer Alasdrach, filius de Axer, Abrahim Moratalli, alias Usmeni, Yayu Ata, alias Alamany, Abrahim Jafer, filius de Abrahim, Ali Gatneri, alias Aparici, Axer Alisar, alias Cureyet, Mahomat Maszuet, major dierum, Azmet Naia, Maymo Adari, Cilim Uleym, Mahomat Uleym, Onda, filius de Cat, Ali Ayeix, ferrerius, Azmet Moratali, Mahomat Alisar, Miques Mahomat, Bayaya Efucey Curt, omnes simul et quilibet nostrum insolidum parte ex altera, gratis et scienter nos dicte parte per nos et omnes heredes et succesores quoscumque $\operatorname{sim} u$ et insolidum pacto speciali solempni stipulacione. Interveniente notario subscripto tanquam publica et auttentica persona per vobis et omnibus illis quorum interest intereril aut interesse poterit quomodolibet in futurum legittime recipiente et acceptante facimus, inhimus et contrahimus inter nos dictas partes, $\operatorname{sim} u$ l et insolidum ad invicem et vicissim, presentes et acceptantes capitula et contractus pactavos et concordatas singulariter et distructe comemoratis in capitulis subscriptis. Que quide $m$ capitula in presencia nostrum parcium $m$ praerterrea per notarium infrascriptum fuerunt llecta et publicata et sint tenoris sequentis.

Capítols fets e fermats, pactats e concordats per e entre lo spectable senyor don Johan Roiz de Corella, comte de Cocentayna, de una part, Catdon Benjat, Azmet Ilel, Azmet Maymo, àlias Carabaces, Azmet Amer, Cat Atech, Abrahim Alisar, Miques Alí, Xiti Axer, Alisar, lo sartre (sic), Axer Alisar (sic), fill de Axer// ${ }^{\text {no }}$, Abrahim Moratalli, àlias Usmeni, Yayu Ata, àlias Alamany, Abrahim Jafer, fill de Abrahim, Alí Gatneri, àlias Aparici, Axer Alisar, Cureyet, Mahomat Maszuet, major, Azmet Naja, Maymo Adari, Cilim Uleym, Mahomat Uleym, Onda, fill de Cat, Alí Ayeix, ferrer, Azmet Moratali, Mahomat Alisar, Miques Mahomat, Bayaya Fucey Curt, moros comorants en lo lloch de Muro, terme de la villa e comdat de Cocentayna, de la part altra, en e sobre lo stabliment fahedor per lo dit spectable senyor comte als sobredits moros de les terres e casses romanints al dit spectable senyor comte en lo lloch de Torballos són los següients:

[1-] E primerament és stat pactat e concordat per entre les dites parts que lo dit spectable senyor comte stablirà, axí com ab los presents scrits e capítols stablix, lo dit lloch de Torballos als sobredits moros, exceptat lo que ja.ls és stat stablit, segons que affronta ab lo barranch que devalla del port d'Albayda fins a la puntta del barranch del Noguer, e puja barranch amunt nomenat del Garrofer, fins a la muntanya de Penyacadell, ab terme de Belgida e terme de Albayda, com l'altra part del dit lloch de Torballos és stat ja stablit a dits moros del lloch de Muro a ús e consuetut de bons adquissidors, a cens de set cafficos de forment a corrent, fadiga e luysme. En lo qual dit stabliment lo dit spectable comte ha de ésser tengut de ferma e legal evictió, axí simpla com pactata, ordenadora a tota utilitat e profit dels dits moros, juxta stil e pràtica del notari rebedor dels presents capítols.

[2-] Item, és pactat e concordat entre les dites parts que los dits moros sien tenguts de donar e paguar $/{ }^{\text {to }}$ cascú d'ells per si e per lo tot al dit spectable senyor comte sctze mila huyl cents sous de reyals de València per entrada del dit stabliment. En aquesta forma: co és la mitat lo primer dia de janer del any MDXVII e l'altra mitat lo altre primer dia del mes de janer del 
any MDXVIII. Dels quals dits setze milia huyt-cens sous los sobredits moros ne tinguen de fermar obligació ab executori llargo modo ab les clàusules acostumades.

[3-] Item, és pactat e concordat per e entre les dites parts/ que los dits moros, axí de les casses del dit lloch com de la terra plantada e no plantada, puixen entre ells fer tantes parts e heretats com bén vist los serà, donant a cascuna de les dites heretats e no trocos de terra part del cens que necessari serà, e que puixen dins un any e mig entre ells dividir, partir, vendre e concambiar e fer actes de regonexensa, dins lo qual dit temps de any e mig, de huy en avant comptador, dits moros no sien tenguts e obligats de demanar licència ni de paguar lo dret del luysme; e passat lo termini de any e mig sien obligats de paguar luysme e demanar licència de la fadiga o fadigues a sa senyoria de les vendes, particions, alienacions, concanis (sic) que de allí avant se faran, e acò sots pena de comís.

[4-] Item, és pactat e concordat [per] e entre les dites parts que en lo dit stabliment no y sia e compressa la cassa de senyor ni terc de delme, com aquella dita cassa e terc de delme resten en domini e senyoria del dit espectable comte e dels seus, ensemps ab les dites luysmes e fadigues.

[5-] Item, per quant la almàcera stà dins la cassa de senyor $/ /^{v o}$ e aquella sia compressa en lo dit stabliment e sia de dits moros, és pactat e concordat que los dits moros puixen fer un portal en la part que està devers lo port de Albayda, e lo portal que stà devers la cassa de senyor se haia de tanquar; restant la dita almàcera e areus de aquella en domini útil dels dits moros e no al dit senyor comte, com a sa senyoria reste la directa senyoria.

[6-] Item, és pactat e concordat entre les dites parts que los dits moros puixen, sens encórrer en pena de comís, traure les olives del dit lloch de Torballos, en fer oli dins lo dit comptat on bén vist los serà; e axí mateix tots los altres blats a batre fora dit lloch de Torballos, puix paguen a sa senyoria dit terc de delme. E per lo semblant, los dits moros o qualsevol de aquells, sens encórrer en pena alguna de comís, puixen possar olives dins dit lloch de Torballos per via de fer oli ab e altre blats a batre.

[7-] Item, és pactat e concordat entre les dites parts que los dits moros, axí mateix sens encórrer en pena alguna de comís com àlias, puixen qualsevol de aquells arranquar o tallar qualsevol ley de arbres exceptat les oliveres, com aquelles no puixen arranquar sinó scombrar e adobar, co és a bén millorar e no pijorar a tota utilitat e profit de la senyoria directa.

[8-] Item, és pactat e concordat entre les dites parts que als dits mors (sic), ni als qui aprés posehiran dites terres e casses, no-ls puixa ésser impossat dret algú, axí // de gabella per les oliveres que en dit lloch són e seran per temps, com peyta, e zissa e altres drets, com lo dit senyor comte los stablex franchs de aquells de la forma e manera que sa senyoria o posehia e no en altra manera.

[9-] Item, és pactat e concordat entre les dites parts que los dits moros sien tenguts de donar e paguar los dits set caffís de forment a corrent al dit senyor comte dins lo dit comdat de Cocentayna, en aquell lloch o en aquella part on sa senyoria o sos officials manara $n$, comencant a fer la primera pagua lo dia de la Verge Maria de Agost del any mil D y setze, e de allí avant cascun any en lo dit [dia] e termini.

[10-] Item, és pactat e concordat entre les dites parts que los dits moros, e los que aprés posehiran dites terres e casses, puixen star e habitar en lo dit lloch de Muro e tenir casses en Torballos per a fems e que no sien tenguts ne obligats d'estar ab ses mullers en dites casses de Torballos sinó lo temps que bén vist los serà. E per lo semblants puixen traure los fems sens encórrer en pena alguna, axí de comís com àlias, del dit lloch [e] territori de Torballos per femar les terres de aquells fora dit lloch de Torballos.

[11-] Item, és pactat e concordat entre les dites parts que qualsevol qui starà e habitarà en lo dit Iloch de Torballos ab sa cassa e cap maior e aquell tal posehirà miga heretat que aquell tal haia de pa-//vo guar bessant axí com paguaven los moros qui staven en Torballos e no pus; co és tres sous quatre diners, e acò sia entés de moro qui no pagua bessant en altra part.

[12-] Item, és pactat e concordat entre les dites parts que en lo present stabliment hi sia 
entés e comprés lo erbatge, com aquell sia dels dits moros, exceptat que les calonies e clams que si faran, axí dels dits moros com de persones privades, no sia tolta ni llevada la part de la senyoria com aquella dita part no sia compressa en lo present stabliment. E axí mateix és pactat e concordat que los dits moros puixen possar guardià a voluntat de aquells e llevar aquell tota hora que bén vist los serà.

[13-] Item, és pactat e concordat per e entre les dites parts que los dits moros puixen ussa (sic.) de la carneceria o de les preheminències de aquella, sia segons lo dit spectable senyor comte ne ha ussat, com la dita carneceria e útil de aquella resta e sien dels dits moros senyors de aquella dita carneceria.

[14-] Item, és pactat e concordat entre les dites parts que los moros qui staran en lo dit lloch de Torballos ab son domicilli e cap maior no sien tenguts ni obligats a ninguna servitut de senyor, axí en lo dit lloch de Torballos com en lo dit comdat, axí com és servitut de llenya, obra, correus, cavar la vinya, acuts, com altra qualsevol servitut, exceptat bessant, tota manera de servitut lo dit spectable senyor comte los ne $/ /^{\text {ro }}$ fa franchs e exemps.

[15-] Item, és pactat e concordat entre les dites parts que los presents capítols sien executoris, ab submissió e renunciació de propri for, variació de juhí e clàusules jurades de no llittigar ni impetrar, sots pena, ultra la pena de per fur, en pena de cinch-cents florins de or.

Quibus quidem capitulis, lectis et publicatis e per nos dictos (sic) partes intellectis, nos dicte (sic) partes simul et insolidum llaudantes, facientes et firmantes predicta capitula et contractus in eis et eorum singulis concordatos, pactatos, continuatos et scriptos et omnia et singula et eorum singulis singulem et distructe concordata, promissa, pactata et stipulata sint per nos et omnes heredes et succesores nostros quoscumque $\operatorname{sim} u l$ et insolidum, pacto et stipulacione predictis. Promittimus una pars nostrum, alteri et altera, alteri atque juramus scilicet nos, dictus Johannes Roiz de Corella, comes predictus, juramus ad dominum Deum et ejus Sancta Quatuor Evangelia manu nostra corporaliter tacta; et nos, dicti agareni, juramus ad dominum Deum et alquiblam Mafomati versis faciebus nostris ad meridiem proferentes verba ydonea et sufficiencia ad juramentum agarenorum prestanda, omnia et singula in predictis capitulis et eorum singulis singulim et distructe concordata, promissa, pactata, stipulata quatinus ad utrannque nostrum parcium predictarum pertineant et expectent pertinere et spectare videantur singula suis singulis $/ /^{\circ}$ referendo tenere et observare et addimplere quemadmodum in predictis capitulis et eorum singulis et in contractibus ibi exressis ( sic) continuata, comemorata et scripta sunt et nullo utrique tempore infringere, revocare eis contradicere palam vel oculte aliqua racione vel causa.

Si vero aliqua pars nostrum predicta capitula et eorum singula et omnia et singula in eis et eorum singulis pactata, concordata, promissa et stipulata non observaverit et adimpleverit aut non curaverit quemadmodum concordatum, pactatum, promissum, stipulatum fuit in predictis capitulis et eorum singulis pacto et stipulacione predictis ab sim aliqua intimacione etcetera, ultra penam perjuri incidat et inmitet penam quingentorum folrenorum (sic) anri (sic) ut resti posideris de bonis alterius partis nostrum parcium predictarum inobedientis et predicta omnia et singula suppradicta et infrascripta in predictis capitulis et eorum singulis pactata, promissa et stipulata non observaverit et imaverit quod de impleantur et ab serventur exhigendorum et parti nostrum parcium predictarum parenti (sic) obedienti et adimplenti applicandorum et solvendorum pro pena et nomine pene et pro dopnis et interesse tamen ita per dictas partes pacto et impulante (sic) predictis acudsit et conventum ratto pacto manente etcetera.

Ad quorum omnium etcetera fiat executori llarge cum fori submissione proprii fori renunciacione, judicii variacione et cum clausulis juratis non littigandi et impetrandi etcetera, sub pena predicta etcetera, fiat executori ut dictum est superius etcetera. Pro quibus om $n$ ibus etcetera, nos dicte partes, ad invicem et vicissim et viceversa et $\operatorname{sim} u l$ et insolidum, obligamus omnia et singula / $/{ }^{\mathrm{ro}}$ bona et jura nostra et cujuslibet $\operatorname{sim} u$ l et insolidum mobilio etcetera.

Renunciantes quantum ad hec beneficiis cedendarum accionum, novarum constitucionum Epistole Divi Adriani et Foro Valencie de principali etcetera, et llegi unde queritur fecerunt 
comodari etcetera, et legi admo prode re judicata fecerunt scripta si post ad dictum etcetera, et facultati oblacionis bonorum etcetera.

In quorum fidem et testimonium jussimus de premissis predictum et subscriptum not $a$ rium presens publicum confici instrumenti de quoquisque nostrum sitam publicam consimilem pergamentam et fide dignam habeat formam.

Quod est actum in portico misquite loci de Muro, termini dicte ville Cocentaine.

Testes hujus rei sunt quo ad firmas omnium predictorum, excepto ad firmam dicti Abrahim Jafon qui non firmavit, magnificus Johannes Ferric, miles, Johannes Domingues, vicinus et habitatores Cocentayne, et Abrahim Gime, alias Panades, vicinus morerie Xative comorans in loco de Muro, termini ville Cocentayne.

Presens ceda premissorum capitulorum in precedentibus quatuor (corregido sobre tribus) cartulis cum presenti pagina papireis scripta sunt abstracta a prothocollo mei Ludovici Johannis de Alcamora, auctoritate regia notarii publici, ejusdem receptoris, manu aliena fuit scripta et in ejus originali fidelim comprobata, omni fides indubia ubique adhibeatur hic oppono meum solitum artis notarie sig(signo notarial)num.

Constat de suprapossito in secunda pagina presentis clausure ubi suprapositum quatuor et Ilineatum tribus. 